\title{
Anatomic Stage IIIA Breast Cancer AJCC v8
}

National Cancer Institute

\section{Source}

National Cancer Institute. Anatomic Stage IIIA Breast Cancer AJCC v8. NCI Thesaurus.

Code C139542.

Stage IIIA includes: (T0, N2, M0); (T1, N2, M0); (T2, N2, M0); (T3, N1, M0); (T3, N2, M0).

T0: No evidence of primary tumor. T1: Tumor measuring $20 \mathrm{~mm}$ or less in greatest dimension. T2: Tumor measuring more than $20 \mathrm{~mm}$, but not more than $50 \mathrm{~mm}$ in greatest dimension. T3: Tumor measuring more than $50 \mathrm{~mm}$ in greatest dimension. N1: Tumor with micrometastases; or metastases in 1-3 axillary lymph nodes; and/or clinically negative internal mammary nodes with micrometastases or macrometastases by sentinel lymph node biopsy. N2: T umor with metastases in 4-9 axillary lymph nodes; or positive ipsilateral internal mammary lymph nodes by imaging in the absence of axillary lymph node metastases. M0: No clinical or radiographic evidence of distant metastases. Imaging studies are not required to assign the M0 category. (AJCC 8th ed.) 